\title{
A review on Sero diversity and antimicrobial resistance patterns of Shigella species in Africa, Asia and South America, 2001-2014
}

Atsebaha Gebrekidan Kahsay ${ }^{*}$ and Saravanan Muthupandian

\begin{abstract}
Background: Shigella, gram negative bacterium, is responsible for Shigellosis/bacillary dysentery. It is a global concern although it predominates in developing countries. These are Shigella dysenteriae, Shigella flexneri, Shigella boydii and Shigella sonnei. Drug resistance by Shigella species is another headache of the world. Therefore; this study aimed to review distribution of Shigella Serogroups and their antimicrobial patterns carried out in Africa, Asia and South America.

Methods: A literature search was performed to identify published studies between January 2001 and December 2014. Published studies were identified using an initial search of the MEDLINE/Index Medicus Database, PubMed, Project Management Consultant, Google Scholar, Science Direct, BioMed Central and Index Copernicus.

Results: Shigella flexneri was isolated predominately from seven studies in four African countries and eight studies in five Asian countries. The countries in which eligible studies carried out were Ethiopia, Kenya, Eritrea and Ghana in Africa and Pakistan, Iran, China, Nepal and India in Asia. S. sonnei was isolated predominately from one study in Africa, four in Asia and two South America. The countries in which eligible studies carried out were Ethiopia from Africa, Thailand, Vietnam and Iran from Asia and Chile and Trinidad from South America. S. dysentery was also reported majorly from one eligible study in Egypt and one in Nepal. S. boydii did not score highest prevalence in any one of the eligible studies. Three studies from Africa, five from Asia and one from South America were reviewed for antimicrobial resistance patterns of Shigella Serogroups. In all the regions, Ampicillin developed highly resistance to almost all the Serogroups of Shigella whereas all the strains were sensitive to Ciprofloxacin.
\end{abstract}

Conclusion: The incidence of Shigella Serogroups in the selected three regions is different. The domination of S. flexneri is observed in Africa and Asia although S. sonnei in South America is dominant. Shigella Serogroups are becoming resistance to the commonly prescribed antimicrobial drugs in developing countries.

Keywords: Serogroups of Shigella, Antimicrobial resistance

\section{Background}

Shigella, a group of Gram-negative, non-spore forming and rod shaped bacterium, is the causative agent of shigellosis (or bacillary dysentery). Shigella Serogroups are

\footnotetext{
*Correspondence: atseba_mu@yahoo.com

Department of Medical Microbiology and Immunology, Institute of Biomedical Sciences, College of Health Sciences, Mekelle University, Mekelle, Tigray, Ethiopia
}

considered to be highly infectious due to their low infectious dose (10-100 organisms) [1]. Shigella is primarily transmitted through the fecal-oral route; therefore, it is still a main global public health threat, particularly in developing countries due to poor sanitation conditions [2].

Shigella bacteria are serologically grouped into four species named as Shigella dysenteriae, Shigella flexneri, Shigella boydii and Shigella sonnei. However Serogroups of Shigella bacteria have similar property of pathogenesis 
and epidemiologically they have peculiar characteristics. S. flexneri found predominantly in developing world, while $S$. sonnei is the most common species found in the industrialized countries [3]. The severity of Serogroups of Shigella is different one from the other that $S$. sonnei and $S$. flexneri cause mild infection whereas $S$. boydii and S. dysenteriae cause severe and most serious infection respectively [2]. The infection caused by S. sonnei and $S$. boydii lasts with short duration and mostly found in industrialized countries. The distribution of Shigella son$n e i$ in the United States of America is 74-79 \% [4] and $61 \%$ in Europe [5].

The emerging of multi drug resistance is becoming a serious problem in the treatment of shigellosis. An increment of multidrug resistance to shigellosis is equivalent to a widespread uncontrolled use of antibiotics in developing countries. This emergency of drug resistance calls for the rational use of effective drugs and underscores the need for alternative drugs to treat infections caused by resistant strains [6].

Shigella is more associated with low socio economic status and poor sanitation of under developed countries [2]. Researches were done by different researchers concerning the Serogroups and antimicrobial susceptibility patterns of Shigella in Africa, Asia and South America as a result this study aimed in reviewing the distribution of Serogroups of Shigella and the resistance patterns of antimicrobial drugs which were conducted in the developing countries in the past 14 years.

\section{Methods}

\section{Search strategy and selection criteria}

A literature search was performed to identify published studies between January 2001 and December 2014. Published studies were identified using an initial search of the MEDLINE/Index Medicus Database, PubMed, PMC, Google Scholar, Science Direct, BioMed Central and Index Copernicus.

The study initially screened all unique publications for eligibility based on the relevancy of the title and then screened the full manuscripts for inclusion and exclusion criteria. The following Keywords were used to search all the published papers from the above engines. These were Prevalence, isolation, Sero diversity, occurrence, epidemiology, Magnitude, burden, estimation, distribution, diversity and antimicrobial resistance patterns of Shigella. Studies conducted before 2001 and researches which concerned only prevalence and antimicrobial susceptibility patterns of Shigella were excluded.

\section{Data extraction}

The first author, country, year of publication, setting, sample size, children and all age, sample source, prevalence and distribution of Serogroups of Shigella were extracted from the eligible studies. Ampicillin, Tetracycline, Chloramphenicol, Ciprofloxacin, Cotrimoxazole, Nalidixic acid and Gentamicin resistance patterns of the four Sero groups of Shigella were extracted from the eligible studies.

Studies were included in the review if they fulfill the following criteria:

- Isolation and identifying of Shigella from stool samples should be based on standard bacteriological methods and Shigella Serogroups were detected serologically using slide agglutination and antimicrobial resistance patterns of Shigella Serogroups should be based on Clinical Standards Laboratory Institute guidelines using disc diffusion methods.

- Full text articles studied in Africa, Asia, and South America and published in English everywhere in the globe were included.

\section{Results}

Majority of the reviewed articles were Hospital based studies. About $40 \%$ of the study participants were children under 15 years old. Stool samples were the source of specimens in all the eligible studies. A total of 69,849 stool specimens' data were collected. Eighteen $(72 \%)$ of the eligible studies were published before 2010 and the rest seven were published from 2010 to 2014 (Table 1).

Shigella flexneri was isolated predominately from Ethiopia [7, 8, 14], Kenya [9, 13], Eritrea [11], Ghana [12], Pakistan [16], Iran [17, 22], China [19, 27], Nepal [23, 28], India [29] and Brazil [31] (Table 1). S. sonnei was also isolated predominately from Ethiopia [13], Thailand [18], Vietnam [24] and Iran [25, 26], Chile [21] and Trinidad [30]. S. dysentery was also reported majorly from Egypt [10] and Nepal [15]. S. boydii did not score highest prevalence in any one of the eligible studies (Table 1).

Shigella sonnei was not isolated from studies conducted in Ethiopia [14] and Nepal [20]. S. dysentery was not isolated from the studies conducted in Ethiopia [14], Thailand [18], China [19, 27], Chile [21], Brazil [31], and Vietnam [24]. S. boydii was not also isolated from the studies conducted in Ethiopia [14], Eritrea [11], Thailand [18], China [19, 27], Chile [21] and Brazil [31] (Table 1).

Nine studies were eligible for antimicrobial susceptibility testing [AST] of Shigella Serogroups. Those are three from Africa, five from Asia and one from South America. In all the regions, Ampicillin developed highly resistance to almost all the Serogroups of Shigella whereas all the strains were sensitive to Ciprofloxacin. Hundred percent of isolates revealed by Orrette in South America were resistance for Ampicillin but $100 \%$ sensitive to 


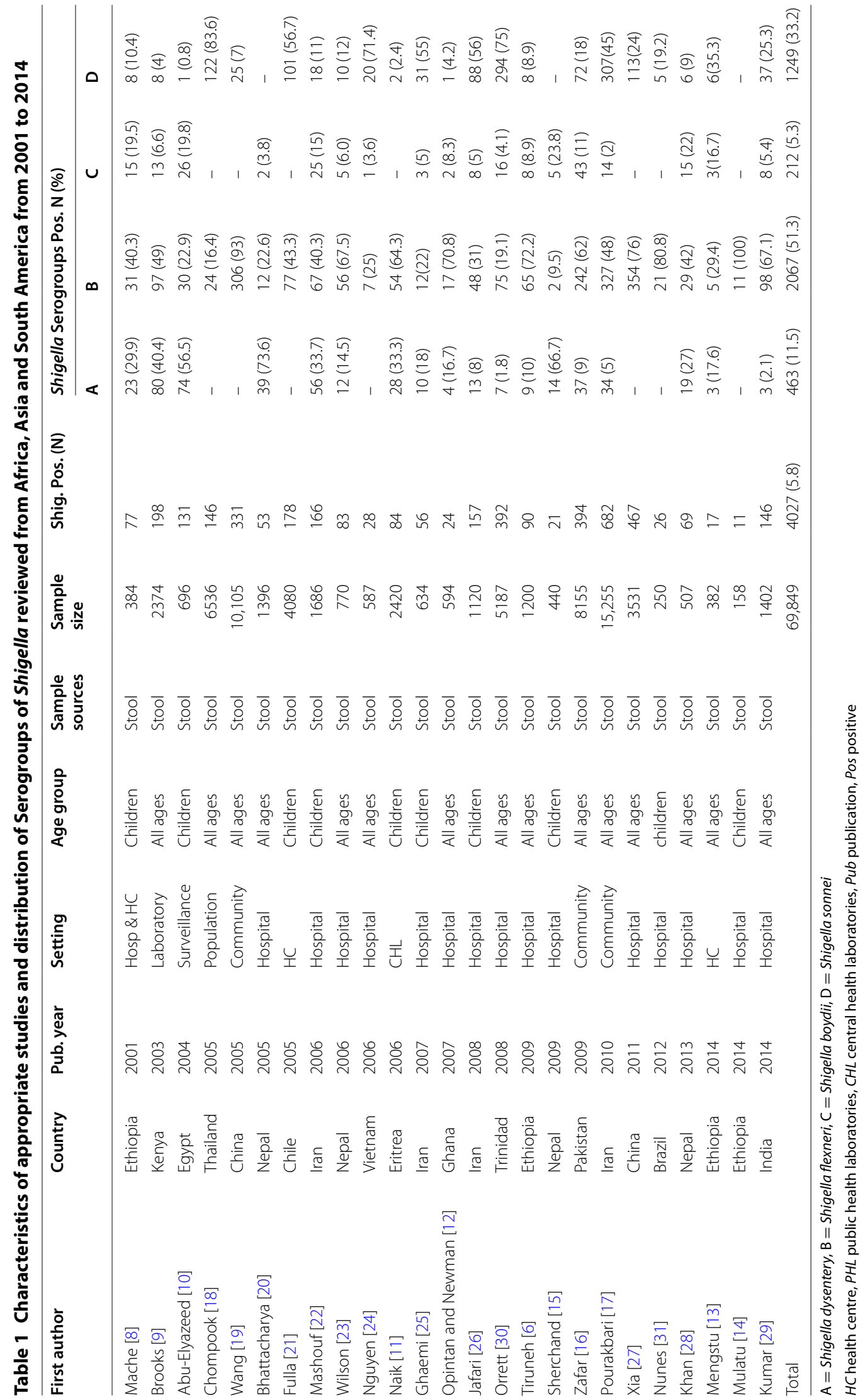


Tetracycline, Chloramphenicol, Ciprofloxacin and Cotrimoxazole (Table 2). In most of the studies observed in Africa (Table 3) and Asia (Table 4), Serogroups of Shigella were developed resistance to Tetracycline, Chloramphencol and Cotrimoxazole.

\section{Discussion}

This review addressed the status of the distribution of the Serogroups of Shigella and antimicrobial resistance patterns conducted in 25 eligible studies reviewed from Africa, Asia and South America.

Shigella flexneri was revealed $100 \%$ from all the eligible studies reviewed in eight African, fourteen Asian and three South American countries. S. dysentery was reviewed from 87, 72 and $33 \%$ of the eight African, fourteen Asian and three South American countries respectively. S. boydii was reviewed from 75,79 and $33 \%$ of the studies carried out in eight Africa, fourteen Asia and three South America respectively. S. sonnei was also reviewed in 87,86 and $100 \%$ of the studies conducted in eight Africa, fourteen Asia and three South American countries respectively (Table 1 ).
Of the total 69,849 stool sample data collected from the 25 eligible studies published from 2001 to 2014, 4027 Shigella bacteria were isolated which is $5.8 \%$. Above $50 \%$ of the proportion of Shigella Serogroups was covered by $S$. flexneri which was followed by S. sonnei (33 \%). S. boydii was contributed five percent of the four Serogroups of Shigella (Table 1).

The pooled mean resistance of $S$. dysentriae to Ampicillin, Tetracycline, Cotrimoxazole, Chloramphenicol, Nalidix acid, Gentamicin and Ciprofloxacin were 72.1, $69.4,60,44,40,17$ and $7 \%$ respectively. The pooled mean resistance of S. flexneri to Tetracycline, Ampicillin, Nalidix acid, Cotrimoxazole, Chloramphenicol, Gentamicin and Ciprofloxacin were 75.8, 75.6, 74.5, 72.7, 51.7, 14.5 and $7 \%$ respectively. The pooled mean resistance of $S$. boydii to Ampicillin, Tetracycline, Cotrimoxazole, Chloramphenicol, Ciprofloxacin, Gentamicin and Nalidix acid were $64,63,48,29,10,6$ and $3 \%$ respectively. The pooled mean resistance of $S$. sonnei to Tetracycline, Cotrimoxazole, Nalidix acid, Ampicillin, Chloramphenicol, Gentamicin and Ciprofloxacin were 79, 71, 54, 47, 35, 16 and $0 \%$ respectively (Table 5 ).

Table 2 Review on antimicrobial resistance patterns of Serogroups of Shigella conducted in South America

\begin{tabular}{|c|c|c|c|c|c|c|c|c|}
\hline \multirow[t]{2}{*}{ Author } & \multirow[t]{2}{*}{ Serogroup } & \multicolumn{7}{|c|}{ Resistance patterns, N (\%) } \\
\hline & & AMP & $\mathbf{T}$ & $\mathrm{C}$ & CIP & NA & SXT & GM \\
\hline \multirow[t]{4}{*}{ Orrett [30] } & S. dysentery & $7(100)$ & $0(0.0)$ & $0(0.0)$ & $0(0.0)$ & - & $0(0.0)$ & $0(0.0)$ \\
\hline & S. flexneri & $36(46)$ & $9(12)$ & $0(0.0)$ & $0(0.0)$ & - & $16(21)$ & $0(0.0)$ \\
\hline & S. boydii & $10(63)$ & $6(38)$ & $3(3.9)$ & $0(0.0)$ & - & $3(19)$ & $0(0.0)$ \\
\hline & S. sonnei & $27(9)$ & $106(36)$ & $4(1.4)$ & $2(0.7)$ & - & $97(33)$ & $4(1.4)$ \\
\hline
\end{tabular}

Table 3 Review on antimicrobial resistance patterns of Serogroups of Shigella conducted in Africa

\begin{tabular}{|c|c|c|c|c|c|c|c|c|}
\hline \multirow[t]{2}{*}{ Authors } & \multirow[t]{2}{*}{ Serogroups } & \multicolumn{7}{|c|}{ Resistance patterns, N(\%) } \\
\hline & & AMP & $\mathbf{T}$ & C & CIP & NA & SXT & GM \\
\hline \multirow[t]{4}{*}{ Mache [8] } & S. dysentery & $17(73.9)$ & $15(64.2)$ & $12(52.2)$ & - & $11(8.7)$ & $9(39.1)$ & $0(0.0)$ \\
\hline & S. flexneri & $22(71)$ & $20(64.5)$ & $13(41.9)$ & - & $3(9.7)$ & $9(29)$ & $1(3.2)$ \\
\hline & S. boydii & $10(66.7)$ & $8(53.3)$ & $4(25)$ & - & $0(0.0)$ & $5(33.3)$ & $0(0.0)$ \\
\hline & S. sonnei & $5(62.5)$ & $6(75)$ & $2(25)$ & - & $0(0.0)$ & $2(25)$ & $0(0.0)$ \\
\hline \multirow[t]{4}{*}{ Tiruneh [6] } & S. dysentery & $8(89)$ & $7(77.8)$ & $1(11)$ & $0(0.0)$ & $0(0.0)$ & 7 (77.8) & $1(11)$ \\
\hline & S. flexneri & $54(83)$ & $62(95.4)$ & $45(69)$ & $2(31)$ & $0(0.0)$ & $59(90.8)$ & $7(10.8)$ \\
\hline & S. boydii & $4(50)$ & 7 (87.5) & $2(25)$ & $0(0.0)$ & $0(0.0)$ & $4(50)$ & $2(25)$ \\
\hline & S. sonnei & $3(37.5)$ & $8(100)$ & $2(25)$ & $0(0.0)$ & $0(0.0)$ & $6(75)$ & $1(12.5)$ \\
\hline \multirow[t]{2}{*}{ Naik [11] } & S. dysentery & $19(95)$ & - & $18(90)$ & $0(0.0)$ & - & $0(0.0)$ & - \\
\hline & S. flexneri & $42(78)$ & - & $34(67)$ & $0(0.0)$ & - & $3(6)$ & - \\
\hline
\end{tabular}


Table 4 Review on antimicrobial resistance patterns of Serogroups of Shigella conducted in Asia

\begin{tabular}{|c|c|c|c|c|c|c|c|c|}
\hline \multirow[t]{2}{*}{ Author } & \multirow[t]{2}{*}{ Serogroups } & \multicolumn{7}{|c|}{ Resistance patterns, N (\%) } \\
\hline & & AMP & $\mathbf{T}$ & $\mathrm{C}$ & CIP & NA & SXT & GM \\
\hline \multirow[t]{2}{*}{ Wang [19] } & S. flexneri & $292(95.4)$ & - & - & $18(5.9)$ & $305(99.7)$ & $206(67.3)$ & $7(2.3)$ \\
\hline & S. sonnei & $2(8)$ & - & - & $0(0.0)$ & $24(96)$ & $24(96)$ & $0(0.0)$ \\
\hline \multirow[t]{3}{*}{ Bhattacharya [20] } & S. dysentery & $32(82.1)$ & - & - & $13(33.3)$ & $33(84.6)$ & $35(89.5)$ & - \\
\hline & S. flexneri & $12(100)$ & - & - & $2(16.7)$ & $4(33.3)$ & $11(91.7)$ & - \\
\hline & S. boydii & $2(100)$ & - & - & $1(50)$ & $0(0.0)$ & $1(50)$ & - \\
\hline \multirow[t]{4}{*}{ Mashouf [22] } & S. dysentery & $54(96.4)$ & $50(89.2)$ & $52(92.8)$ & $3(3.5)$ & $48(85.7)$ & $52(92.8)$ & - \\
\hline & S. flexneri & $63(94)$ & $61(91.1)$ & $61(91.1)$ & $0(0.0)$ & $3(44.7)$ & $59(88.1)$ & - \\
\hline & S. boydii & $17(68)$ & $13(52)$ & $21(84)$ & $0(0.0)$ & $0(0.0)$ & $15(60)$ & - \\
\hline & S. sonnei & $15(83.3)$ & 15 (83.3) & $17(94.4)$ & $0(0.0)$ & $7(38.8)$ & $14(77.7)$ & - \\
\hline \multirow[t]{2}{*}{ Wilson [23] } & S. dysentery & $6(75)$ & 7 (87.5) & $5(62.5)$ & $1(12.5)$ & $5(62.5)$ & $51(100)$ & $6(75)$ \\
\hline & S. flexneri & $33(64.7)$ & $49(96)$ & $23(45.1)$ & $1(2)$ & $16(31.4)$ & $8(100)$ & $34(66.7)$ \\
\hline \multirow[t]{3}{*}{ Jafari [26] } & S. dysentery & $3(37.5)$ & $8(100)$ & $0(0.0)$ & $0(0.0)$ & $0(0.0)$ & $7(87.5)$ & $0(0.0)$ \\
\hline & S. flexneri & $23(47.9)$ & $46(95.8)$ & $23(47.9)$ & $0(0.0)$ & $0(0.0)$ & $42(87.5)$ & $2(4)$ \\
\hline & S. boydii & $5(38.4)$ & $11(84.6)$ & $1(7.6)$ & $0(0.0)$ & $2(15.4)$ & $10(76.9)$ & $0(0.0)$ \\
\hline
\end{tabular}

Table 5 Pooled range and mean of antimicrobial resistance patterns of Shigella Serogroups

\begin{tabular}{|c|c|c|c|c|c|c|c|c|c|c|c|c|c|c|}
\hline \multirow{3}{*}{$\begin{array}{l}\text { Serogroups } \\
\text { of Shigella }\end{array}$} & \multicolumn{14}{|c|}{ Resistance (\%) } \\
\hline & \multicolumn{2}{|l|}{ AMP } & \multicolumn{2}{|l|}{$T$} & \multicolumn{2}{|l|}{$C$} & \multicolumn{2}{|l|}{ CIP } & \multicolumn{2}{|l|}{ NA } & \multicolumn{2}{|l|}{ SXT } & \multicolumn{2}{|l|}{ GM } \\
\hline & PR & PM & PR & PM & PR & PM & PR & PM & PR & PM & PR & PM & PR & PM \\
\hline S. dysentery & $37.5-100$ & 72.1 & $0-100$ & 69.4 & $0-92.8$ & 44.1 & $0-33.3$ & 7 & $0-85.7$ & 40.3 & $0-100$ & 60.8 & $0-75$ & 17.2 \\
\hline No. of studies & 8 & & 6 & & 7 & & 7 & & 6 & & 8 & & 5 & \\
\hline S. flexneri & $46-100$ & 75.6 & $12-95.8$ & 75.8 & $0-91.1$ & 51.7 & $0-31$ & 7 & $0-99.7$ & 74.1 & $6-100$ & 72.7 & $0-66.7$ & 14.5 \\
\hline No. of studies & 9 & & 6 & & 7 & & 8 & & 7 & & 9 & & 6 & \\
\hline S. boydii & $38.4-100$ & 64.4 & $38-87.5$ & 63.1 & $3.9-84$ & 29.1 & $0-50$ & 10 & $0-15.4$ & 3.1 & $19-76.9$ & 48.2 & $0-25$ & 6.3 \\
\hline No. of studies & 6 & & 5 & & 5 & & 5 & & 5 & & 6 & & 4 & \\
\hline S. sonnei & $8-83.3$ & 46.9 & $36-100$ & 79.4 & $1.4-94.4$ & 35.4 & $0-0.7$ & 0.12 & $0-96$ & 54.8 & $25-100$ & 71.9 & $0-12.5$ & 16.6 \\
\hline No. of studies & 7 & & 6 & & 6 & & 6 & & 6 & & 6 & & 6 & \\
\hline
\end{tabular}

AMP Ampicillin, $T$ Tetracycline, C Chloramphenicol, CIP Ciprofloxacin, NA Nalidixic acid, SXT sulphamethoxazole trimethoprim/Cotrimoxazole, GM gentamicin, PR pooled range, $P M$ pooled mean, No Number

Above $50 \%$ of all Serogroups of Shigella developed resistance to Ampicillin, Tetracycline, Cotrimoxazole and Chloramphenicol which are the commonly prescribed antimicrobial drugs.

\section{Conclusions}

The incidence of Shigella Serogroups in the selected three regions is different. The domination of S. flexneri is observed in Africa and Asia although S. sonnei, the most dominant in South America, is predominately isolated in one study in Ethiopia. This may give clue to the scientific world about the migration and movement of strains from one region to the other region. Shigella Serogroups are becoming resistance to the commonly prescribed antimicrobial drugs in developing countries.

Authors' contributions

Both AK and SM contributed to the drafting of the manuscript. Both authors read and approved the final manuscript.

Acknowledgements

None.

Competing interests

The authors declare that they have no competing interests.

Ethics approval and consent to participate

Since the data was taken from data bases of different publishers, therefore ethical approval and consent to participate are not applicable. 
Received: 25 March 2016 Accepted: 23 August 2016

Published online: 30 August 2016

\section{References}

1. Baron S. Shigella. In: Hale TL, Keusch GT, editors. Baron's medical microbiology. Galveston: University of Texas; 2000.

2. Mims C, Dockrell HM, Goering RV, Roit I, Wakelin D, Zukerman M. Medical microbiology. 3rd ed. Edinburgh: Elsevier; 2007.

3. Kotloff KL, Winickoff JP, Ivanoff B, Clemens JD, Swerdlow DL, et al. Global burden of Shigella infections: implications for vaccine development and implementation of control strategies. Bull World Health Organ. 1999;77:651-66

4. Center for diseases control, Bacterial Foodborne and Diarrheal Disease National Case Surveillance: Annual Report. Atlanta: USA; 2005. Department of Health and Human Services.

5. European center for diseases control, Annual epidemiological report, 2013, reporting on 2011 surveillance data and 2012 epidemic intelligence data, Stockholm.

6. Fauci AS, Braunwald E, Kasper DL, Hauser SL, Logo DL, Jameson L, Loscalzo J. Harrison's principle of internal medicine. 7th ed. USA: McGraw-Hill Campanies; 2008

7. Tiruneh M. Serodiversity and antimicrobial resistance pattern of Shigella isolates at Gondar University Teaching Hospital Northwest Ethiopia. Jpn J Infect Dis. 2009;62:93-7.

8. Mache A. Antibiotic resistance and Sero-groups of Shigella among pediatric outpatients in Southwest Ethiopia. East Afr Med J. 2001;78:296-9.

9. Brooks JT, Shapiro RL, Kumar L, Wells JG, Phillips-howard PA, Shi Y, Vulule JM, Hoekstra RM, Mintz E, Slutsker L. Epidemiology of sporadic bloody diarrhea in rural Western Kenya. Am J Trop Med Hyg. 2003;68(6):671-7.

10. Abu-Elyazeed RR, Wierzba TF, Frenck RW, Putnam SD, Rao MR, Savarino SL, Kamal KA, Peruski JR, Abd-EL Messih LA, EL-Alkamy SA, Naficy AB, Clemens JD. Epidemiology of Shigella-associated diarrhea in rural Egyptian children. Am J Trop Med Hyg. 2004;71(3):367-72.

11. Naik DG. Prevalence and antimicrobial susceptibility patterns of Shigella species in Asmara, Eritrea, Northeast Africa. J Microbiol Immunol Infect. 2006:39:392-5.

12. Opintan JA, Newman MJ. Distribution of Sero groups and serotypes of multiple drug resistant Shigella isolates. Ghana Med J. 2007;41:4-8.

13. Mengistu G, Mulugeta G, Lema T, Aseffa A. Prevalence and antimicrobial susceptibility patterns of Salmonella serovars and Shigella species. J Microb Biochem Technol. 2014:2:1-7.

14. Mulatu G, Beyene G, Zeynudin A. Prevalence of Shigella, Salmonella and Campylobacter species and their susceptibility patters among under five children with diarrhea in Hawassa town, South Ethiopia. Ethiop J Health Sci. 2014:24:101-8.

15. Sherchand JB, Yokoo M, Sherchand O, Pant AR, Nakogomi O. Burden of enteropathogens associated diarrheal diseases in children hospital Nepal. Scientific World. 2009;7(7):71-5.

16. Zafar A, Hassan R, Nizami SO, Seidlein L, Soofi S, Ahsan T, Chandio S, Habib A, Bhutto N, Siddiqui FJ, Rizvi F, Clemens JD, Bhutta ZA. Frequency of isolation of various subtypes and antimicrobial resistance of Shigella from urban slums of Karachi Pakistan. Int J Infect Dis. 2009:13:668-72.

17. Pourakbari B, Mamishi S, Mashoori N, Mahboobi N, Ashtiani MH, Afsharpaiman S, Abedini M. Frequency and antimicrobial susceptibility of Shigella species isolated in Children Medical Center Hospital, Tehran, Iran. Braz J Infect Dis. 2010:14(2):153-7.
18. Chompook P, Samosornsuk S, Seidlein LV, Jitsanguansuk S, Sirima N, Sudjai S, Mangit P, Kim DR, Wheeler JG, Todd J, Lee H, Ali M, Clemens J, Tapchaisri P, Chaicumpa W. Estimating the burden of shigellosis in Thailand: 36 month population based surveillance study. Bull World Health Organ. 2005;83:739-46.

19. Wang X, Du L, Seidlein L, Xu Z, Zhang Y, Hao Z, Han O, Ma J, Lee L, Ali M, Han C, Xing Z, Chen J, Clemens J. Occurrence of shigellosis in the young and elderly in rural china: results of a 12-month population-based surveillance study. Am J Trop Med Hyg. 2005;73:416-22.

20. Bhattacharya S, Khanal B, Bhattarai NR, Das ML. Prevalence of Shigella species and their antimicrobial resistance patterns in Eastern Nepal. J Health Popul Nutr. 2005;23:339-42.

21. Fulla F, Prado V, Duran C, Lagos R, Levine MM. Surveillance for antimicrobial resistance profiles among Shigella species isolated from a Semirural Community in the northern administrative area of Santiago Chile. Am J Trop Med Hyg. 2005;72:851-4.

22. Mashouf RY, Moshtaghi AA, Hashemi SH. Epidemiology of Shigella species isolated from diarrheal children and drawing their antibiotic resistance pattern. Iran J Clin Infect Dis. 2006;1:149-55.

23. Wilson W, Easow JM, Mukhopadhyay C, Shivananda PG. Isolation \& antimicrobial susceptibility of Shigella from patients with acute gastroenteritis in western Nepal. Indian J Med Res. 2006:123:145-50.

24. Nguyen TV, Van PL, Huy CL, Gia KN, Weintraub A. Etiology and epidemiology of diarrhea in children in Hanoi Vietnam. Int J Infect Dis. 2006;10:298-308

25. Ghaemi EO, Aslani MM, Moradi AV, Dadgar T, Livani S, Mansourian AR, Nosrat SB, Ahmadi AR. Epidemiology of Shigella-associated diarrhea in Gorgan, north of Iran. Saudi J Gastroenterol. 2007;13(3):129.

26. Jafari F, Hamidian M, Rezadehbashi M, Doyle M, Salmanzadeh-ahrabi S, Derakhshan F, Zali MR. Prevalence and antimicrobial resistance of diarrheagenic Escherichia coli and Shigella species associated with acute diarrhea in Tehran, Iran. Can J Infect Dis Med Microbiol. 2009;20:56-62.

27. Xia S, Xu B, Huang L, Zhao JY, Ran L, Zhang J, Chen H, Pulsrikarn C, Pornruangwong S, Aarestrup FM, Hendriksen RS. Prevalence and characterization of human Shigella infections in Henan Province China. J Clin Microbiol. 2011;49:232-42.

28. Khan S, Singh P, Asthana A, Ansari M. Magnitude of drug resistant shigelIosis in Nepalese patients. Iran J Microbiol. 2013;5:334-8.

29. Kumar A, Oberoi A, Alexander VS. Prevalence and antimicrobial susceptibility patterns of Shigella in stool samples in a tertiary healthcare hospital of Punjab. Chrismed J Health Res. 2014;1:33-5.

30. Orrett FA. Prevalence of Shigella Serogroups and their antimicrobial resistance patterns in southern Trinidad. J Health Popul Nutr. 2008;26:456-62.

31. Nunes MRCM, Magalhaes PP, Penna FJ, Nunes JMM, Mendes EN. Diarrhea associated with Shigella in children and susceptibility to antimicrobials. J Pediatr. 2012:88:125-8.

\section{Submit your next manuscript to BioMed Central and we will help you at every step:}

- We accept pre-submission inquiries

- Our selector tool helps you to find the most relevant journal

- We provide round the clock customer support

- Convenient online submission

- Thorough peer review

- Inclusion in PubMed and all major indexing services

- Maximum visibility for your research

Submit your manuscript at www.biomedcentral com/submit
Ciomed Central 